\title{
EXPERIÊNCIAS DE APRENDIZAGEM EM VISITA FAMILIAR À EXPOSIÇÃO “QUANDO NEM TUDO ERA GELO” DO MUSEU NACIONAL A
}

\author{
Luisa Massarani ${ }^{1}$ \\ https://orcid.org/0000-0002-5710-7242 \\ Antero Vinícius Portela Firmino Pinto ${ }^{3}$ \\ https://orcid.org/0000-0002-8693-3690
}

\author{
Julia Botelho Pereira² \\ https://orcid.org/0000-0001-8872-1491 \\ Juliana Magalhães de Araújo $^{3}$ \\ https://orcid.org/0000-0002-6051-7381
}

. 
indican que las familias pudieron desarrollar la comprensión de la exposición y que módulos expositivos de características contemplativas, con un enfoque en objetos y artefactos, contribuyen a la construcción de significado y comprensión de temas relacionados con la ciencia.

\title{
LEARNING EXPERIENCES IN FAMILY VISIT TO THE EXHIBITION “WHEN NOT EVERYTHING WAS ICE" AT THE NATIONAL MUSEUM
}

\begin{abstract}
:
In this paper, we analyse the learning experiences of families visiting a science exhibition through the interactions and conversations. The aim is to understand how an exhibition with a narrative environment design can facilitate the learning process and the construction of meaning of themes related to science. Nine groups of families with children participated in the study, which has a qualitative and exploratory approaches, on a spontaneous visit to the exhibition "When everything was not ice", designed by the National Museum (RJ). The audiovisual records of the visits were analysed with a research protocol that combines theoretical and empirical aspects of the museum experience. Our results indicate that families were able to develop some understanding of the exhibition and that contemplative exhibitions, with a focus on objects and artefacts, can contribute to the construction of meaning and understanding of topics related to science.
\end{abstract}

Keywords:

Science museum;

Exhibitions; Free choice learning.

\section{INTRODUÇÃO}

As famílias vão a museus com múltiplos objetivos. Elas podem estar procurando uma atividade divertida e/ou estar interessadas nas experiências de aprendizagem (Allen, 2002; Borun, 2002; Dierking \& Falk, 1999; McManus, 1994; Moussouri, 1997). Cada família chega ao museu, como definem Pekarik, Doering \& Karns (1999), com uma "narrativa de entrada", ou seja, seus interesses individuais são "trazidos para o museu” pela forma que constroem e contemplam o mundo; cada família tem informaçôes sobre algumas áreas específicas de conteúdo e que, em geral, são sustentadas por experiências pessoais, emoçôes e memórias que contribuem para a compreensão de conteúdos. Cada família traz sua cultura única, com seus conhecimentos compartilhados, valores, experiências e expectativas para o museu (Borun, 2002; Ellenbogen; Luke \& Dierking, 2007; Falk, 2021). E são essas “narrativas de entrada” que direcionam o aprendizado e os comportamentos das famílias no museu (Rowe \& Nickels, 2011).

Neste estudo, a concepção de aprendizagem adotada está pautada em uma perspectiva sociocultural (Cf: Ash, 2003, 2004; Borun et al., 1998; Crowley et al., 2001; Ellenbogen, 2002; McClain \& Zimmerman et al., 2019) que vai além de uma definição comumente presumida de uma mudança cognitiva ou conceitual focada no indivíduo para uma compreensão de aprendizagem vista como um domínio distribuído e social - como resultado de interaçóes entre pessoas e entre as pessoas, os objetos e os ambientes. Ou seja, trata-se de um processo dinâmico com resultados múltiplos, muitas vezes inesperados, que envolve interaçóes socialmente significativas, que incluem motivação, interesse e capacidade do indivíduo de atuar de forma independente, fazendo suas próprias escolhas (Rowe \& Bachman, 2011; Tal, 2012).

Para terem experiências de aprendizagem conjuntas em museus, os integrantes da família precisam negociar o que vão ver e como irão se envolver a partir das exposiçôes (Falk, 2021; Rowe, 2002). Isso porque os 
museus são ambientes que possibilitam e incentivam modos múltiplos de interagir acerca de e com objetos. Além disso, quando as famílias interagem com as exposiçôes, vários fatores contextuais afetam sua experiência de aprendizagem. Entre eles, podemos citar a expectativa, o conhecimento prévio, os interesses e as crenças, a mediação sociocultural dentro do grupo, a mediação facilitada por outros, o design e as experiências fora do museu (Falk, 2000; Falk \& Storksdieck, 2005). Ao estudarmos as experiências e os comportamentos de aprendizagem das famílias em uma visita ao museu e como essa atividade se desenvolve, consideramos as interaçôes verbais e não verbais (ou seja, fala, ação, gestos, manipulações etc.) para entender a atribuição de significado a um fenômeno novo que vê, ouve, contempla ou experimenta de outra forma (McClain \& Zimmerman et al., 2019; Rowe, 2002). Afinal, as famílias são ativamente envolvidas na construção e reconstrução desses contextos e a aprendizagem não é uma experiência abstrata que ocorre em um ambiente esterilizado (Pedretti, 2004), mas "uma experiência orgânica integrada que ocorre no mundo real” (Falk \& Dierking, 2000, p. 10).

Neste estudo, visamos compreender as experiências de aprendizagem subjacentes às práticas das famílias em museus de ciências. Esses espaços têm papel fundamental na aprendizagem de temáticas científicas e no engajamento de diversos públicos com a ciência (Scalfi, 2020), já que possibilitam que os visitantes interajam entre si e nos ambientes expositivos e vivenciem a experiência museal ao mesmo tempo em que se apropriam de temas científicos. Muitos museus de ciências possuem ainda recursos, como coleçôes históricas, que podem fomentar a consciência da relevância da história e da filosofia da ciência para o progresso do conhecimento científico e podem funcionar como poderosas máquinas do tempo, com o potencial de transportar os visitantes mental e emocionalmente para o passado, em que liçóes importantes podem ser aprendidas (Faria et al., 2015; Ramey-Gassert et al., 1994). Nesse sentido, tem havido um esforço de pesquisas que visam entender a construção de sentido por meio da experiência direta com objeto e o papel das interações do visitante com as exposiçóes (Achiam; May \& Marandino, 2004; Jakobsson \& Davidsson, 2012; Shaby et al., 2019; Rowe, 2002;).

Entender a construção e a atribuição de significado pelos visitantes na relação com os objetos pode trazer implicações importantes para o processo de aprendizagem e o impacto das exposiçôes na vida dos visitantes, uma vez que destaca o papel ativo do visitante na construção de sentido de uma experiência de museu por meio do contexto que o indivíduo traz (McClain \& Zimmerman, 2016).). De acordo com Achiam, May, Marandino (2004, p.16), "quando os visitantes dão sentido às suas interações com as exposições, é exatamente no espaço criado por essa conjunção de estruturas ambientais e características do visitante que a construção de significado pode ocorrer”. Dessa forma, a relação dos visitantes entre si e com a exposição proporciona um sistema de cognição distribuído, em que o conhecimento, a prática e a construção de significado são estendidos sobre representações externas (o design da exposição) e internas (percepção interna do visitante) (Jakobsson \& Davidsson, 2012; Rowe, 2002).

Mediante o exposto, o objetivo deste estudo de abordagem quanti-qualitativa e caráter exploratório é compreender como uma exposição com um design de ambiente narrativo em que objetos e espaços se tornam parte de um processo de contar histórias (Hanks; Hale \& Macleod, 2012) pode facilitar o processo de aprendizagem e construção de significado de temas relacionados à ciência. Nosso enfoque está nas interaçôes em família, incluindo as conversas e as ações entre os visitantes e com as exposições - aspectos que são abordados no protocolo de análise e que, por sua vez, estão em diálogo com a concepção de aprendizagem defendida neste estudo.

\section{METODOLOGIA}

Neste estudo, analisamos as interaçôes de famílias em visitas espontâneas a uma exposição intitulada "Quando nem tudo era gelo" - Novas Descobertas no Continente Antártico", desenvolvida pelo Museu Nacional (MN) e montada no Centro Cultural Museu da Casa da Moeda do Brasil (CMB), Rio de Janeiro. O estudo faz parte de uma pesquisa mais ampla, realizada no escopo do Instituto Nacional de Comunicação Pública da Ciência e Tecnologia (INCT-CPCT) e da MUSA Iberoamericana: red de museos y centros de 
ciencia-Cyted, que visa compreender o aprendizado em museus de ciência e os sentidos criados pelos distintos públicos em torno das atividades de educação não-formal oferecidas nesses espaços científico-culturais (Massarani et al. 2019a; Massarani et al., 2019b; Massarani et al., 2019c; Massarani et al., 2020) e conta com apoio do Conselho Nacional de Desenvolvimento Científico e Tecnológico (CNPq) e da Fundação Carlos Chagas Filho de Amparo à Pesquisa do Estado do Rio de Janeiro (Faperj).

\section{A exposiz̧ão do estudo: "Quando nem tudo era gelo" do Museu Nacional}

O Museu Nacional, atualmente vinculado à Universidade Federal do Rio de Janeiro (UFRJ), foi fundado em 1818 e é a instituição científica mais antiga do Brasil. É um dos maiores e mais renomados museus da América Latina, tendo alcançado uma coleção de cerca de 20 milhóes de artefatos de valor científico e culturalmente inestimável (Pires, 2017; Fapesp, 2018).

Com a destruição substancial do seu acervo no incêndio ocorrido em setembro de 2018, a comunidade do museu tem buscado formas de mantê-lo vivo, com a ajuda de diferentes instituições e, assim, reconstituir parte da sua memória (Duarte et al., 2019). Como parte desse resgate, foi inaugurada na CMB a primeira exposição após o incêndio, na qual este estudo foi realizado, com o objetivo de ampliar o acesso às informações sobre o continente Antártico e o trabalho desenvolvido por pesquisadores brasileiros nas expediçóes ao continente gelado. Foram apresentadas informaçôes e fotos relacionadas a memórias de coletas e descobertas científicas de expediçóes realizadas entre 2015 e 2018 pelo projeto PaleoAntar, que está vinculado ao Programa Antártico Brasileiro - ProAntar (Conexão UFRJ, 2019).

A exposição, inaugurada em janeiro de 2019, foi organizada em duas salas, de $136 \mathrm{~m}^{2}$ e $130 \mathrm{~m}^{2}$, respectivamente. Além disso, no saguão de entrada, os visitantes se depararam com uma réplica de um mosassauro - um espécime de cinco metros de comprimento pertencente a um grupo extinto de criaturas marinhas que habitaram os mares do final do período Cretáceo. Ao seguir para a exposição, na primeira sala, os visitantes visualizavam os artefatos científicos e as explicaçôes sobre o ambiente atual e as expedições à Antártica, com detalhes sobre as condições de trabalho dos pesquisadores, seus acampamentos e laboratórios. A sala foi mantida com a temperatura mais baixa do que a da sala seguinte, para dar ao visitante a sensação de se transportar para a Antártica. Entre os objetos expostos, destacamos o crânio de uma baleia-minke, a arcada de tubarão e animais taxidermizados - focas, pinguins e outras aves marinhas - em um iceberg cenográfico, duas barracas e um quadriciclo originais utilizados nas expedições (Figura 1A). Na segunda sala, que se dedicou a remontar o ambiente tropical antártico de cerca de 90 milhóes de anos atrás, os visitantes eram confrontados com uma Antártica pouco conhecida, por meio de réplicas e originais de fósseis de plantas, como samambaias e pinhas, com destaque para o fóssil de plesiossauro, um réptil voador com primeiro registro na Antártica do período Cretáceo. Neste espaço, destaca-se ainda o trabalho realizado pelos paleontólogos e os equipamentos utilizados, bem como fósseis e amostras de rochas. A transição entre as duas salas oferecia aos visitantes uma mudança da paisagem frente a reconstrução paleoclimática e paleoambiental ao longo do tempo (Figura 1B). Das peças em exposição, 160 pertenciam ao Proantar e oito foram resgatadas dos escombros do MN (Fapesp, 2019; Rodrigues, 2019). Não havia trajeto determinado nas salas e os visitantes seguiam seus interesses. 

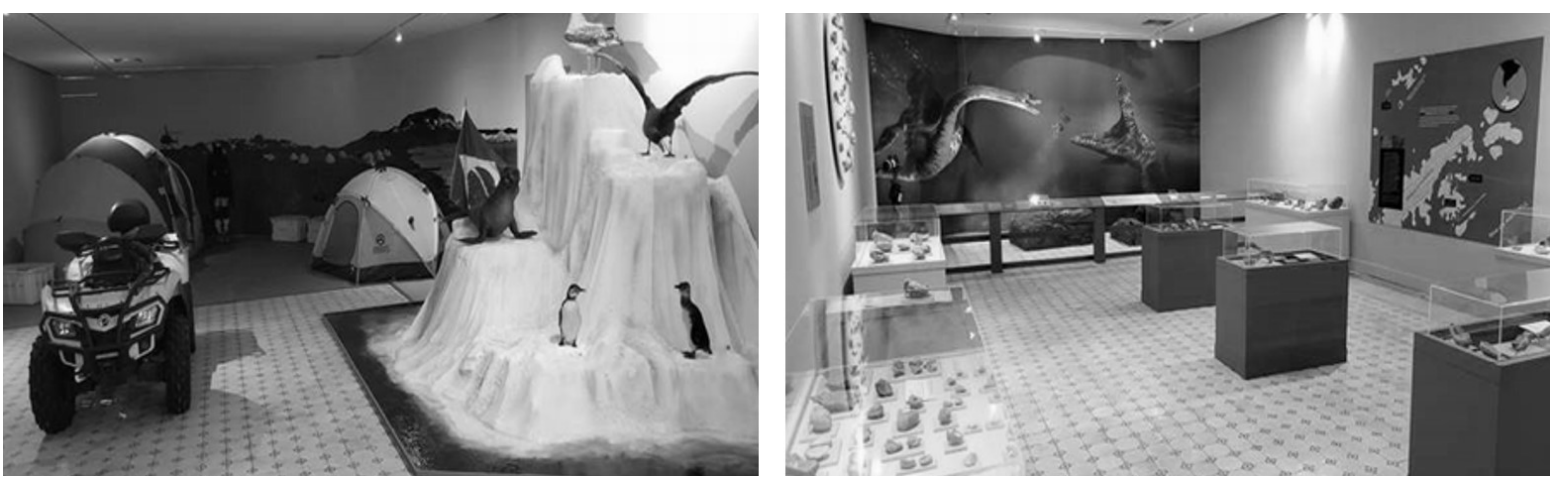

Figura 1. (A) primeira sala da exposição (B) segunda sala da exposição.

Fonte: Centro Cultural Museu Casa da Moeda do Brasil.

\section{Procedimentos}

A coleta de dados ocorreu nos dias 19, 20, 25 e 26 de julho de 2019, em período de férias escolares. Ao entrar no CBM, famílias foram abordadas por um membro da equipe de pesquisa (a definição sobre os critérios para as famílias será mais detalhada no item a seguir). Atendendo os requisitos de pesquisa, explicava-se para os grupos familiares o propósito do estudo e era perguntado se eles gostariam de participar registrando sua visita à exposição.

O presente estudo foi aprovado pelo Comitê de Ética da Fundação Oswaldo Cruz (CAAE 10663419.0.0000.5241). Um dos responsáveis preenchia o Termo de Consentimento Livre e Esclarecido (TCLE), com informaçôes sobre os procedimentos e objetivos de pesquisa. Nenhuma das famílias abordadas recusou o convite. Para registro das interaçôes, um adulto e uma criança de cada grupo foram convidados a usar uma câmera subjetiva do tipo GoPro disposta em um suporte especial colocado na cabeça durante toda a visita. A câmera registrava os dados audiovisuais de toda a família a partir da perspectiva do visitante que a carregava, seguindo o método "point-of-view camera", usado em diversos estudos na área de ciências sociais (Lahlou 2011; Glãveanu \& Lahlou, 2012) e em estudos anteriores deste grupo de pesquisa (Cf: Massarani et al. 2019a; Massarani et al., 2019b; Massarani et al., 2019c; Massarani et al., 2020). Neste estudo, os dados foram codificados a partir do olhar da criança. Ao final da visita, um adulto do grupo preencheu um questionário com dados de perfil sociocultural, interesses e costumes em relação a ciência e tecnologia e também em relação ao Museu Nacional.

\section{Sujeitos do estudo}

Em nosso estudo, um grupo era considerado família quando seus membros intergeracionais eram biologicamente relacionados ou eram considerados família pelos membros do grupo (Briseño-Garzón \& Anderson, 2012). Cada grupo deveria ter pelo menos um adulto e uma criança. Restringimos o número de integrantes da família a cinco sujeitos, para potencializar a captura dos diálogos e açóes dos familiares por meio das câmeras e gravadores. A delimitação da faixa etária de criança foi feita com base no Estatuto da Criança e do Adolescente, que define criança como a pessoa até 12 anos de idade incompletos (Brasil, 1990). Optamos por incluir crianças a partir de sete anos, por considerar que é nessa fase da infância que ela passa por um processo de transição em relação às atividades de estudo, como o processo de alfabetização, e, portanto, uma idade em que elas são introduzidas a conhecimentos novos, em que surgem o pensamento teórico, a consciência e outras funções, como a capacidade de reflexão e planificação mental (Elkonin, 1978; Vigotsky, 1993). Dessa forma, espera-se que expressem seus pontos de vista e opinióes na medida em que o discurso expositivo e o contexto sociocultural proporcionem. 
Participaram do estudo nove grupos familiares, compostos por 24 sujeitos, sendo dez do sexo feminino (sete adultas e três crianças) e 14 do sexo masculino (cinco adultos e nove crianças). Seis famílias residiam no município do Rio de Janeiro. Entre aquelas que vinham de fora do município do Rio de Janeiro, uma família era proveniente de Niterói e a outra de Itaperuna. Uma das famílias era de Balneário Camboriú (Santa Catarina). A Tabela 1 a seguir sistematiza as informaçóes sobre os grupos familiares:

Tabela 1. Informações dos membros dos visitantes de cada Grupo familiar

\begin{tabular}{|c|c|c|c|}
\hline GRUPOS & LOCALIZAÇÃO & $\begin{array}{l}\text { NÚMERO DE } \\
\text { INTEGRANTES }\end{array}$ & GÊNERO/IDADE \\
\hline G1 & Balneário Camboriú (SC) & 2 & $2 \odot(51,10)$ \\
\hline G2 & Itaperuna (RJ) & 4 & $3 \odot(39,10,9) ; 1 \%(37)$ \\
\hline G3 & Ramos, Rio de Janeiro (RJ) & 3 & $2 \&(75,8) ; 1 \odot(50)$ \\
\hline G4 & Anchieta, Rio de Janeiro (RJ) & 4 & 3 कా $(42,11,8) ; 1 \&(35)$ \\
\hline G5 & Centro, Rio de Janeiro (RJ) & 2 & 1\% (44); 1 कా (9) \\
\hline G6 & Cordovil, Rio de Janeiro (RJ) & 2 & $2 \&(37,8)$ \\
\hline G7 & Niterói (RJ) & 2 & 2 कृ $(64,9)$ \\
\hline G8 & Irajá, Rio de Janeiro (RJ) & 2 & 1\& (38); 1 (10) \\
\hline G9 & Bonsucesso, Rio de Janeiro (RJ) & 3 & $2 \&(42,7) ; 1 \odot(7)$ \\
\hline
\end{tabular}

Fonte: Autoria própria.

A escolaridade dos adultos tem a seguinte distribuição: quatro possuíam educação superior em nível de graduação e dois pós-graduação; três tinham ensino médio completo. Um tinha ensino médio incompleto; um fez ensino fundamental e um não informou a escolaridade. As crianças, estudantes de ensino fundamental, dividiram-se entre estudantes da rede pública (7) e rede privada (5) de ensino.

As famílias relataram ter o hábito, ainda que não assíduo, de visitar espaços científicos-culturais. Cinco famílias disseram que visitam espaços de ciências, museus e exposiçóes mais de uma vez ao ano; quatro grupos informaram visitar esse tipo de espaço pelo menos uma vez ao ano. Entre os principais espaços visitados citados pelas famílias estão o Museu do Amanhã (4), o Museu Nacional (3), o Museu Histórico Nacional (3) e o Centro Cultural do Banco do Brasil (2). Três das nove famílias participantes visitaram o MN cinco ou mais vezes ao ano; outras quatro famílias relataram visitas anuais, mas em menor número. As outras duas famílias não souberam dizer o número de visitas ao $\mathrm{MN}$. Quando questionadas sobre o que recordavam de suas visitas anteriores ao $\mathrm{MN}$, as famílias responderam lembrar de fósseis, meteoritos, animais, múmias e objetos que remetiam à história do Brasil. A arquitetura do MN também foi recordada por duas famílias.

\section{Análise de dados}

Como instrumento de análise, utilizou-se um protocolo desenvolvido pela rede de pesquisadores envolvidos no projeto, que, por sua vez, foi adaptado de investigaçóes realizadas por Allard e Boucher (1998). Os autores argumentam que o museu tem por finalidade auxiliar o visitante a se tornar competente, ou seja, capaz de se apropriar do museu durante sua experiência interativa de modo autônomo - tanto na escolha do objetivo quanto na maneira de atingi-lo. Para isso, é preciso entender as relaçôes entre três atores fundamentais do museu, (i) os artefatos (módulos expositivos), (ii) os atores do museu (mediadores) e os (iii) visitantes. Neste estudo, tomamos como base os três atores proposto por Allard e Boucher (1998) e desenvolvemos um protocolo para análise de conversas e interaçôes dos visitantes de museus. O protocolo de análise e codificação está dividido em 
cinco dimensões: (1) Conversação, (2) Interação, (3) Fotos, (4) Mudança e (5) Emoçãa, sendo as dimensões 1 e 2 trabalhadas neste artigo (Tabela 2). A opção deste protocolo de pesquisa reside no fato de ele dialogar com as perspectivas socioculturais a que nos referimos no referencial teórico, em que a aprendizagem é vista como um processo, com múltiplos resultados, que incluem motivação, interesse, conversas e interações, que vai além do tempo que os visitantes permanecem no museu. Além disso, está em consonância com estudos que investigam esses temas em museus, como Ash, 2003; Crowley et al., 2001; Ellenbogen, 2002; Falk \& Dierking, 2000; Jakobsson \& Davidsson, 2012; Rowe \& Bachman, 2011; Tal, 2012; Silverman, 1995 e Wagensberg, 2001. Esse protocolo foi validado por seis pesquisadores, responsáveis por sua aplicação e seu formato final, e aplicado até o momento em 13 museus de ciência interativos latino-americanos, mostrando-se útil para a área de estudo de público (Massarani et al. 2019a; Massarani et al., 2019b; Massarani et al., 2019c; Massarani et al., 2020).

Tabela 2. Dimensões das categorias de análise da pesquisa

\section{CONVERSAÇÕES}

1.1 Conversas sobre temas de ciência

1.2 Conversas sobre a exposição e temática não científica

1.3 Conversas sobre exposição (funcionamento, design, experiência museal)
Diálogos sobre algum tema científico, discutem dilemas éticos e morais da ciência, impacto social da atividade científica, trazem dados ou conteúdos científicos etc.

Diálogos sobre temáticas que são abordadas pela exposição, mas que não se referem a temas de ciência previstos na categoria acima.

Diálogo desencadeado a partir da interação dos visitantes com a exposição e/ou os módulos expositivos, seja sobre seu funcionamento, design e/ou experiência museal.

1.4 Conversas não relacionadas ao conteúdo da exposição

Abordagem de temas não relacionados diretamente à visita.

1.5 Conversas sobre carreiras profissionais

Menção à escolha de carreira profissional (na área científica ou não).

Mobilização, utilização, questionamento sobre seus próprios conhecimentos, crenças, rituais, modos de vida, na experiência museal, fazendo referência a vivências da infância, conhecimentos da escola; referências a filmes, livros, séries e programa de TV etc.

1.6 Conversas em que se faz associação com experiências anteriores e vivência pessoal

Discussão sobre a forma como acontece a mediação, como observadores externos.

1.7 Conversas sobre a mediação

\section{TIPOS DE INTERAÇÃO}

2.1 Visitante-módulo expositivo

2.1.1 Atividade interativa

A interação se dá pela: imersão; experimentação; interação física (apertar botões, girar manivelas etc.) necessárias para a continuidade da narrativa/enredo/conteúdo do módulo; controle de variáveis e interferência no resultado/produto do módulo; e/ou jogo.

2.1.2 Interação contemplativa

Contemplação, observação, visualização sem toque/manipulação de um módulo expositivo ou parte dele específico.

2.1.3 Leitura de painel/texto/foto explicativo

A interação se dá pela leitura em voz alta de textos (integrais ou parte) de placas informativas, painel, legenda, texto, charge dos módulos expositivos. 
Para análise dos resultados, fizemos uso do software de análise quanti-qualitativa Dedoose 8.0.23, que auxilia a categorização de segmentos de áudio e vídeo das ações corporais, textuais e atitudinais dos visitantes de maneira simultânea, otimizando a codificação. No software, foram identificados os trechos de cada uma das atividades e 1040 aplicações de códigos foram contabilizadas. Um código pode ocorrer em sobreposição a outro, visto que as categorias do protocolo de análise não são excludentes e podem acontecer simultaneamente em uma experiência museal. Para a identificação dos sujeitos, garantindo o anonimato, foram utilizados os seguintes códigos: a letra " $G$ ” para a identificação do grupo familiar, "A" para visitante adulto e "C" para visitante criança, sendo o indivíduo número 1 sempre aquele que estava portando a câmera. As codificaçốes deste estudo em particular foram validadas por três pesquisadores envolvidos no estudo durante a etapa de codificação no software de análise.

\section{RESULTADOS}

Os dados das interações dos grupos familiares durante a visita à exposição contabilizaram 185 minutos de vídeos analisados. Em média, o tempo de visita de cada grupo familiar foi de 19 minutos. A Tabela 3 mostra as categorias/subcategorias com maior destaque na análise e o tempo de ocorrência de cada código.

Tabela 3. Tempo e ocorrência total das conversas registradas nas principais categorias analisadas

\begin{tabular}{|c|c|c|c|}
\hline CATEGORIAS/SUBCATEGORIAS & OCORRÊNCIA & $\begin{array}{l}\text { TEMPO DE } \\
\text { OCORRÊNCIA }\end{array}$ & $\begin{array}{c}\text { \% EM RELAÇÃO AO } \\
\text { TEMPO DOS VÍDEOS } \\
\text { ANALISADOS }\end{array}$ \\
\hline \multicolumn{4}{|l|}{ 1. CONVERSAÇÕES } \\
\hline 1.1 Conversas sobre temas de ciência & 155 & $10 \mathrm{~min}$ & $6 \%$ \\
\hline $\begin{array}{l}1.2 \text { Conversas sobre exposição } \\
\text { (funcionamento, design, experiência museal) }\end{array}$ & 79 & $3 \mathrm{~min}$ & $2 \%$ \\
\hline $\begin{array}{l}1.3 \text { Conversas em que se faz associação com } \\
\text { experiências anteriores e vivência pessoal }\end{array}$ & 24 & $1 \mathrm{~min}$ & $1 \%$ \\
\hline
\end{tabular}

2.1 Visitante-módulo expositivo

\begin{tabular}{|c|c|c|c|}
\hline 2.1.1 Atividade interativa & 42 & $9 \min$ & $5 \%$ \\
\hline 2.1.2 Interação contemplativa & 122 & $81 \mathrm{~min}$ & $44 \%$ \\
\hline $\begin{array}{l}\text { 2.1.3 Leitura de painel/texto/foto } \\
\text { explicativo }\end{array}$ & 117 & $20 \mathrm{~min}$ & $11 \%$ \\
\hline 2.2 Visitante-Visitante & 328 & $45 \mathrm{~min}$ & $25 \%$ \\
\hline
\end{tabular}

Fonte: Autoria própria.

Entre os códigos de análise mais registrados nos trechos de vídeos analisados, estão: Interação visitante-visitante (328 vezes), Conversas sobre temas de ciência (155 vezes), Interação contemplativa (122 vezes) e Leitura de painel/texto/foto explicativo (117 vezes), como é possível observar na Tabela 3. Outros códigos foram menos frequentes, como Atividade interativa ( 42 vezes), Conversas sobre a exposição ( 79 vezes) e Conversas em que se faz associação com experiências anteriores e vivência pessoal (24 vezes). A partir desses dados, detalhamos, a seguir, as circunstâncias em que tais categorias ocorreram. A interação visitante-visitante ocorreu intensamente ao longo de toda a visita à exposição. As famílias conversaram entre si durante a maior parte da visitação. Em relação ao padrão de visita, em algumas famílias, as crianças permaneceram 
próximas aos familiares, enquanto em outras elas foram mais autônomas na exploração, porém, elas sempre retornavam para compartilhar suas observaçôes. Entre os comportamentos, a leitura, o apontar para identificar os organismos expostos e para chamar a atenção do outro para mostrar algo foram recorrentes nos grupos familiares, como pode ser visto nos exemplos a seguir.

\section{Quadro 1. Exemplos de interação Visitante-visitante}

Exemplo 1 - (G2): C1: "Pai aquilo ali éum ganso?” / A1: “Não, aquilo ali é um albatroz.” / C1: "Como você sabe?”. / A1: "É porque [trecho incompreensível] a gente, sabe né? Os nomes estão ali, isso aqui é uma foca." / C1: "Eles são muito realistas, os pinguins." / A1: "Vem cá, vem cá, ó."/ A1: "1, lobo do mar." \{Leitura\} [Em seguida ele aponta para o lobo do mar e diz] "é aquele bicho ali.” [...]"2, albatroz gigante.”\{Leitura\} [aponta novamente em direção do iceberg e diz] "Tá vendo o albatroz, aquele ali em cima. Tá vendo o que papai falou, éo dois, aquele lá em cima, ó, com a plaquinha 2." \{Leitura\}... "3, petrel antártico, 4 e 5, pinguim de Magalhães." \{Leitura\}.

Exemplo 2 - (G5): A1: “São os instrumentos da expedição, né?"/ C1: Mãe, mãe, mãe, olha, isso aqui tá cum negocinho de pó [chama a atenção da mãe para algo que vê] / A1: "Aqui, oh, o pessoal trabalhando." / C1: "Olha picareta, mãe, olba a picareta [...] olha a pá, olha o tamanho da pá". / A1: "Olha o tamanho dessa bota... a lá o pessoal trabalhando"

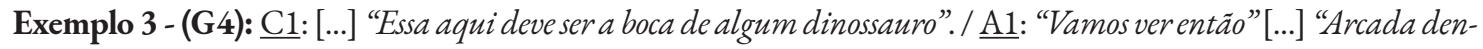
tária de tubarão, alguns dentes, fósseis encontrado na Antártica." \{Leitura\} / A1: "Foram encontradas, éum fóssil, olha o dente de tubarão. /C1: "Isso aqui não um tubarão, éum megalodonte." /

A exposição foi organizada com um design informativo e contemplativo, com painéis de leitura e artefatos, como maquetes, mapas, réplicas e fósseis de dinossauros, modelos de animais que habitam o continente atualmente, fotos e vídeos sobre as expediçốes e sobre os pesquisadores, que tinham a intenção de contar uma história - o que justifica a expressividade do código Interação contemplativa (44\%). Entre esses objetos e elementos utilizados na exposição, alguns despertaram maior interesse e curiosidade por parte das famílias, a saber: o plesiossauro, as réplicas de animais sobre os icebergs, os fósseis de moluscos (amonoides e nautiloides) e os esqueletos de animais, como a baleia-minke e a arcada de um tubarão touro. A seguir, exemplos que ilustram essas ocorrências.

Quadro 2. Exemplos de conversas relacionadas à Interação contemplativa com os objetos

Exemplo 4 - (G6): [C1 entra na sala 2 e vê o modelo de plesiossauro] C1: Mãe vem cá, vem cá, olha o que eu achei... muito legal! [observa o plesiossauro] Olha mãe! / A1: Que lindo! Về com calma, olhe com calma, presta atenção.

Exemplo 5 - (G3): $\underline{\mathrm{C} 1:}$ «É concha?» / $\underline{\mathrm{A} 1:}$ "Não, esses são fósseis que são achados dentro das.."./C1: "conchas" $\underline{\mathrm{A} 1:}$ "das conchas". "É tipo um caracol". /C1: "Olha lá! fizeram uma concha" [aponta e contempla o mural com amonitas] / $\underline{\mathrm{A} 1:}$ "Esses são os dinossauros"/ C1: “Cruzes, que medo!!”/ A1: "Pterossauros, são os pterodáctilos”/C1: “Aiiii, dá um meedo, heim?”/ A1: "Esses são do fundo do mar. Ele comia aquele bichinho lá que tá ali” [aponta para o painel com o mosassauro e o plesiossauro] /C1: "Hummm"[Contempla o modelo e repete em voz alta e com dificuldade] Pterodáctilo.

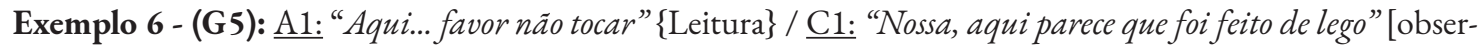
vando a vitrine maquete de navios da marinha] "Nossa, mãe!"/ A1: "réplica em escala reduzida, você também já estudou escala reduzida, lembra? dos navios da marinha do Brasil que dão suporte ao programa antártico brasileiro" / $\mathrm{C} 1:$ "Tá, olha aqui agora aqui, mãe" / $\underline{\mathrm{A} 1:}$ "Olha, crânio de baleia" [observando o crânio de baleia-minke] / C1: "Cruz credo, tchau [não se aproxima do crânio], Olha mãe, nossa!" [aponta para os animais taxidermizados no iceberg. A mãe se aproxima e ambos observam a representação] $\underline{\mathrm{A} 1:}$ : "Eu acho que ela está empalhada"/ $\mathrm{C} 1$ : " $A$ foca?" [apontando para o lobo-marinho]/ A1: Ubum. 


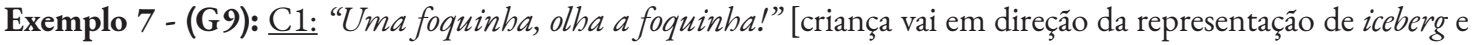
a mãe para a maquete dos navios] / A1: "Olha aqui, C1, aqui os navios da marinha que dão suporte ao programa Antártico brasileiro"... [a mãe segue para representação do iceberg] / $\underline{\mathrm{A} 1:}$ Que fofo isso gente! / $\underline{\mathrm{C} 1:} \mathrm{O}$ quê?? / $\underline{\mathrm{A1}}$ : "a

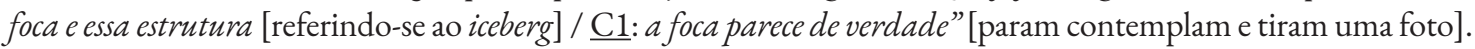

Exemplo 8 - (G9): C1: "Olha mãe! Ob meu Deus! [repete impressionado] Isso não éo que estou pensando, olha aqui mãe [mãe está na outra sala]. Isso não éo que estou pensando [repete 4x]. Não épossivel!' Mãe vem cá, não estou acreditando! [demonstra entusiasmo]. Vem cá, corre [repete 3x], vem [repete 5x]. Olha a boca de um tubarão!" / A1: "É de tubarão?" / $\underline{\mathrm{C} 1:}$ "É, eu acho que é, tá parecendo". / $\underline{\mathrm{A} 1:}$ : Arcada dentária de um tubarão touro" $\{$ Leitura\} / C1: "Falei, eu sou especialista [mãe pede pra tirar uma foto] Perai, deixa eu analisar esses dentes".

Nos exemplos apresentados, embora haja diferenças em seus detalhes, podemos verificar que a experiência de visita proporcionou às famílias a presença de momentos de admiração e observação. Tal experiência desencadeou nos visitantes diferentes respostas pessoais, que vão desde um comportamento mais introspectivo (observam, realizam a leitura em silêncio e não comentam ou expressam seus sentimentos e pensamentos com os demais familiares) até respostas que traziam as expressões de emoção ("Que legal”, "Que lindo!", "Cruz credo!”, “Que medo", “Nossa!’, “Oh, meu Deus!”, "Não estou acreditando!”) e a relação com os conhecimentos científicos (tanto expostos quanto prévios dos visitantes) desencadeados por um objeto ou cenário da exposição.

Outro elemento importante na interação das famílias com a exposição está na expressividade do código Leitura de painel/texto/foto explicativo, presente em $11 \%$ do tempo da visita. Como a exposição não contava com mediadores, os textos explicativos, legendas e informaçóes sobre a exposição foram elementos importantes, trazendo incrementos, seja para discussóes e o entendimento das famílias sobre os objetos expostos, seja para aproximação de novas informações sobre a Antártica. Uma evidência da importância da leitura está na sua coocorrência com os códigos: Visitante-visitante (74 vezes) - as famílias realizavam a leitura enquanto interagiam entre si; Interação contemplativa (63 vezes) - as famílias liam enquanto observavam e/ou contemplavam; e Conversas sobre temas da ciência (46 vezes) - enquanto liam, conversas de temas da ciência foram mencionadas, fato esperado, visto a proposta da exposição.

As famílias se dedicaram tanto à leitura das legendas (composta por nomes dos fósseis encontrados nas vitrines identificados com numeração arábica sequencial dada a cada um deles, a localidade em que foram coletados e a sua idade geológica) quanto dos painéis explicativos (textos expostos ao lado de algum objeto específico ou na parede para destacar um determinado assunto). A leitura das legendas, de maneira geral, era breve, mas acontecia de forma que auxiliava as famílias na identificação dos organismos e suas características ( $c f$. Exemplos $9,10,11$ e 12). Por sua vez, a leitura dos painéis expositivos, se comparadas às legendas, foi mais longa e trouxe informações sobre o tema científico da exposição de maneira mais contextualizada e, ainda, auxiliou as famílias a estabelecerem conversas sobre o tema ou assuntos diversos ( $c f$. Exemplos 13, 14 e 15). Nem todas as famílias leram as informaçôes dos painéis na íntegra e em voz alta: algumas permaneceram em silêncio, demonstrando um comportamento de leitura (que é de difícil mensuração, por isso não contabilizado neste estudo).

\section{Quadro 3. Exemplos de interação por meio da leitura - legendas e painéis}

Exemplo 9- (G4): A1: “Dente do tubarão touro. \{Leitura\}. Tá escrito aqui filho. [aponta para a legenda] [...] 1 lagosta.”

Exemplo 10 - (G6): A1: "Fósseis apresentados da forma como são encontrados pela equipe \{leitura\}. Fragmento coral, conchas maritimas" \{Leitura\} [aponta para a legenda e fóssil para identificar] / C1: "Ah deixa eu ler! Conchas". \{leitura\}/ A1: "Amonitas". \{leitura\} "Olha aqui o 3" [apontando para a legenda]. "Conchas de amonita" \{leitura\}. 
Exemplo 11 - (G6): A1: "E você sabe o que é isso aqui?”/ $\underline{\mathrm{C} 1:}$ "Não!" / A1: "Pra saber vocêt tem que ler" [apontando

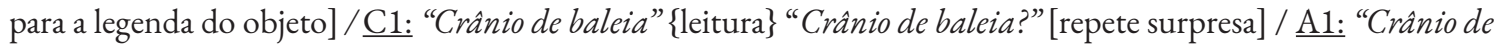
baleia!" / C1: "Isso dai nem parece uma baleia, mas élegal". [...] A1: "Aqui ó [tocando em sua própria cabeça], éo nosso crânio". / $\underline{\mathrm{C} 1:}$ «É isso?» / $\underline{\mathrm{A} 1:}$ "É essa parte da cabeça da baleia".

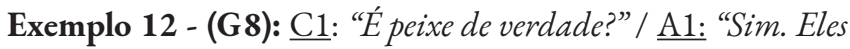
estão dentro de um líquido, se você ler." / $\underline{\mathrm{C} 1:}$ "A tá ali[...] que tipo depeixeséesse?". / A1: "Ali filho, tem escrito o nome de todo eles, ó."

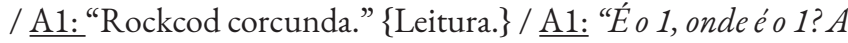
lá, ó. Ai o 2..." \{Leitura de legenda\}. / A1: "Peixe sem lábio. Três, rockcod esmeralda. Quatro, peixe-gelo." / $\mathrm{C} 1:$ "Gigante, esse ai é gigante." / A1: "Cinco, Rockcod listrado. Bacalhau. \{Leitura\} / C1: "Esse aqui éo bacalbau?" / A1: "É!" C1: "Esse aquiéo seis, não esse aqui é o sete, né? Esse aqui éo sete."

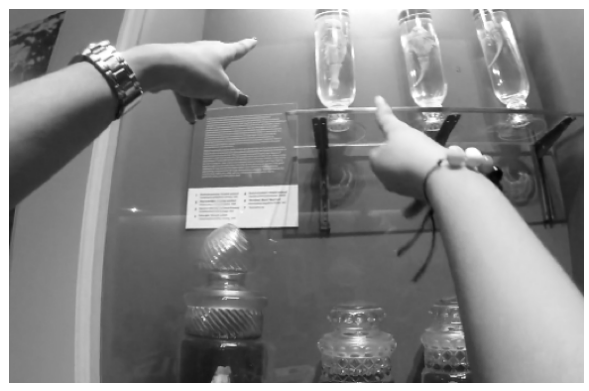

Exemplo 13 - (G5): A1: "Os grandes blocos de gelos, chamados icebergs são fragmentos de geleiras que se soltam e viajam pelas correntes oceânicas nas águas ao redor da Antártica." "Leitura\} / $\underline{\mathrm{C} 1:}$ "Apenas 10\% do tamanho total dos icebergs fica visivel acima da superficie da água, o que os torna extremamente perigosos para navios que circulam ao seu redor." \{Leitura\} / A1: "A água que descongela dos icebergsse mistura com os dos oceanos, liberando nutrientes que influenciam na vida marinha." \{Leitura\}/ C1: "Estudos recentes mostraram que em torno dos icebergs está repleto de plâncton, peixes e outros animais marinhos." \{Leitura\}

Exemplo 14 - (G1): A1: “Fitoplâncton, aqui ob!”’Leitura) [painel: Vivendo sobre o gelo]. "A base da cadeia alimentar da Antártica" \{Leitura\}, "aquele ali”... / C1: "É o plâncton aquele ali”. / A1: ..."é ele e alimento do».../ C1: "Plâncton, grill, peixes orcas, foca leopardo" \{leitura\} [apontando e identificando os animais do painel em uma cadeia alimentar] / A1: "Oh, esse aqui serve de alimento para os pássaros, pinguins, focas, peixes... que os peixes são alimentos da orca e da foca leopardo...Show!..” " 45 espécies de aves \{Leitura\} aqui tá falando... oh, o pinguim imperador" / C1..."que a gente viu lá naquela outra exposição. 1,20m de altura" \{Leitura\} lembra que a gente viu?

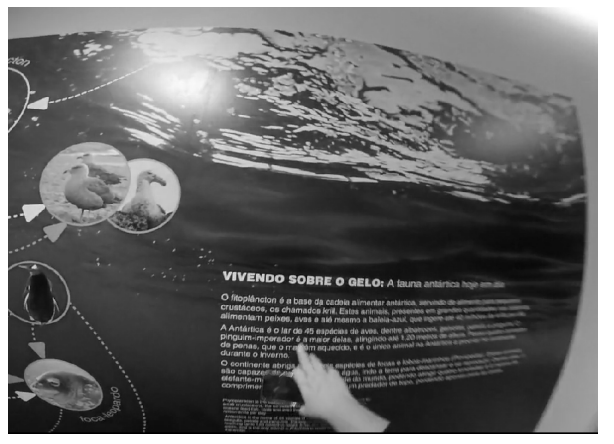

Exemplo 15 - (G5): A1: "Com um corpo enorme, quatro nadadeiras poderosas e um pescogo longo e sinuoso, os plesiossauros vagavam pelos mares em todo mundo entre cerca de, 203 milhöes e 65 milhöes de anos atrás, alcançando o hemisfério sul em meados do periodo Jurássico (bá 85 milhöes de anos). Os animais tinham uma variedade de tamanho entre 1,5 e aproximadamente 15 metros, possuindo algumas caracteristicas que os diferenciavam entre si, como tamanho das cabeças, os pescogos longos ou curtos, assim como o formato do seu corpo" \{Leitura\}. / C1: "Olha ali outro. Ô mãe, mãe, mãe. Já pensou tu tá nadando de boas no mar, tu vês esse esse bicho tirando a cabeça pra fora, tu se depara com esse bicho, o que tu tenta fazer? / A1: Eu só aceito a morte, por que não vai dar não, esse bicho é grande pra caramba." / C1: "Ese você encontra com aquele bicho, o que vocêfaz?" / A1: "A C1, eu entrego pra Deus e rezo, só."

Fotos: Prints de tela da gravação de vídeos de C1 (G8) e C1(G1), respectivamente.

Os exemplos 9, 10, 11 e 12 confirmam como as legendas proporcionaram uma identificação dos animais de forma rápida e com pouca contextualização e/ou aprofundamento sobre o que as famílias visualizavam.

Há três exemplos com comportamentos de leitura distintos. No exemplo 13 do G5, mãe e filho realizam a leitura do painel sobre os icebergs com muitas informaçóes científicas, mas não aprofundam o conteúdo abordado após a finalização da leitura. No exemplo seguinte (14), temos clara uma forma de uma leitura que não é realizada na íntegra e de forma linear, mas em que as imagens do painel auxiliam mãe e filho a entende- 
rem as informações sobre a cadeia alimentar de maneira contextualizada. Já no exemplo 15, após a leitura do conteúdo científico, mãe e filho estabelecem um diálogo em que fazem uso da imaginação sobre o plesiossauro, mostrando ainda que nem sempre os diálogos são aprofundados ou ficam dentro do tema proposto, mas que oferecem insumos para conversas que relacionam conhecimentos científicos, informaçóes e imaginação - sendo um rico processo para as experiências de aprendizagem em família. Assim, há famílias que trazem seus conhecimentos prévios, vivencias e memórias, características únicas, individuais e pessoais para a discussão.

A Atividade Interativa foi menos expressiva, com $5 \%$ de frequência nos vídeos analisados, visto a natureza da exposição, que dispunha de apenas alguns objetos que podiam ser tocados. Uma parte da exposição que despertou a curiosidade foi a reprodução de um acampamento, montado com material original de campo cedido pela Marinha do Brasil: duas barracas - sendo uma disponibilizada para a entrada dos visitantes -, um quadriciclo, no qual o público podia subir, e uma manequim expondo roupas térmicas utilizadas nas missóes da Antártica. Este módulo expositivo proporcionou maior interatividade física (toque, manipulação e imersão) quando comparado ao restante da exposição. Assim, despertou a curiosidade e levou a diálogos em que as famílias demonstram sentimentos positivos frente à experiência proporcionada (Exemplos 16, 17 e 18). Os outros dois momentos de interação física proporcionados pela exposição incluíram um painel para sentir o relevo antártico e um fóssil de amonita tátil. Esses módulos foram explorados pelas famílias de maneiras distintas, sendo algumas individualmente, outras coletivamente, como demonstrado pelos diálogos dos exemplos 19 e 20.

\section{Quadro 4. Exemplos de Atividade Interativa}

Exemplo 16 - (G9): 소: "Pode entrar na cabana. Olha isso."/ $\underline{\mathrm{A} 1:}$ "Preciso de um negócio desse grandão, cara."/1: "Tem até milho, tem água, tem coisa de comer." /A1: "Vem, C2, vem ver, pode. você está acompanhando."/1: "Tem mesa de verdade aqui dentro." / A1: "Por quê o meu celular está descarregado, né?"/C1: "Mas a gente está gravando, né?" / A1: "Igual a nossa barraca grandona, né C2? Vamos comprar outra?" / C1: "Aham, vamos."

Exemplo 17 - (G5): C1: "Sobe aqui baby," / $\underline{\mathrm{A1}}$ : "Ai meu Deus, vai me dar uma carona?”/ $\mathrm{C1}$ : "Isso aqui não vai andar?"/ A1: "Claro que isso não vai andar, é lógico que não?" [ri]/C1: "A não ser que a gente ligue aqui”/ verdade ele dá para uma pessoa aqui, segurando aqui" / $\underline{\mathrm{C} 1:}$ "Ou pode ser assim também... não, tá maluca?” / $\underline{\mathrm{A} 1:} \mathrm{O}$ quê? Para para para A1: "Não acontece nada"/C1: Vai que se de repente ele resolve ligar... tipo que se dane, vou ligar, a vontade é minha... nossa agora eu vou sair daqui.

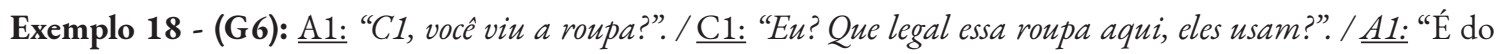

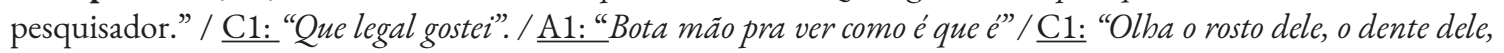
os óculos. Olha gente, a roupa é muito linda. Olha a mãozinha, ai que vontade de apertar. / $\mathrm{A1}$ : "Lá é muito frio, ai precisa de uma roupa especial." / $\underline{\mathrm{C} 1:}$ "Olha, mãe, o tênis dele, que fofo, en gostei."

Exemplo 19 - (G7): A1: "Esse aqui pede pra tocar, pra sentir" / C1: "Sentir o que? / A1: "... as características. Na realidade a concha está dentro da pedra, tá vendo?" / $\underline{\mathrm{C} 1:}$ "Sim, tô" / $\underline{\mathrm{A} 1:}$ "Ai eles acharam...o que que acontece, eles

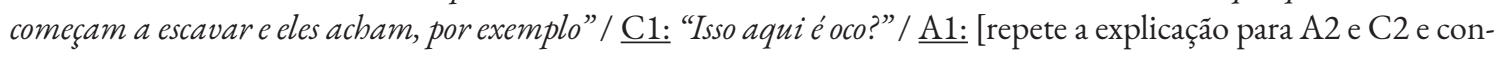
tinua] ... "através da pedra eles vão saber quantos anos têm... assim, por exemplo, os animais aqui têm tantos milhôes de anos...entendeu? dai eles vão saber quanto anos os animais têm, porque às vezes eles perguntam como que éque sabe quantos anos têm?... por isso tem aquelas medidas, existe uma leitura do tipo..." 


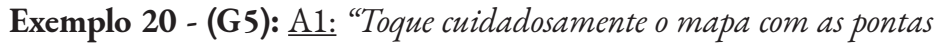
dos dedos para sentir os relevos antárticos $\{$ Leitura $\} ..$. "Nossa essa exposição é maravilhosa, pode tocar nas coisas, tudo o que você estudou, filho." / $\mathrm{C} 1$ : África, Antártica, nossa, Ilha de [...], América do Sul. / A1: "Punta Arenas."/1: "Oceania, acho que isso aqui é uma parte também da Oceania. Nossa uma estrela do mar aqui. Nossa, que musiquinha maneira."

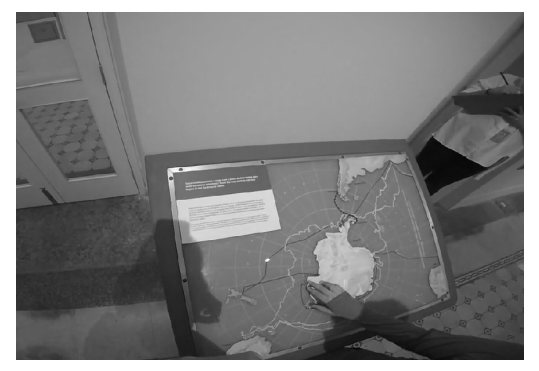

Fotos: Prints de tela da gravação de vídeos de C1 (G5).

As Conversas sobre temas de ciência corresponderam a 6\% (identificados em 155 trechos, em um total de 10 minutos) das interações nos grupos de famílias analisados e indicam comportamentos e experiências de aprendizagem que as famílias construíram na interação entre si e apoiados pela exposição. Esses dados numéricos indicam que apesar de esse tipo de conversa ter acontecido por breves momentos (se comparado ao total de gravações), eles aconteceram em vários episódios - sendo o código mais marcado do nosso protocolo de pesquisa. Identificamos duas maneiras principais (que ocorreram isoladas ou associadas em um mesmo diálogo) em que Conversas sobre temas de ciência foram mais frequentes nesses grupos familiares. A primeira foi pela leitura, como já mencionamos e exemplificamos no código Leitura de painel/texto/foto explicativo - e trouxe para as conversas ideias, fatos, dados ou conteúdos científicos propostos pela exposição. A segunda maneira está pautada em uma experiência de aprendizagem no museu que envolve aspectos físicos, intelectuais, sociais e emocionais (Falk \& Dierking, 2012), e que pode contribuir para construção de sentido entre os familiares. Dessa forma, destacamos como os artefatos, os objetos ou outros elementos expostos foram importantes para que conversas relativas à ciência envolvessem a criação de sentido (Allen, 2002; Rahm, 2002). A seguir, exemplos dessas ocorrências.

Quadro 5. Exemplos de Conversas sobre temas de ciência

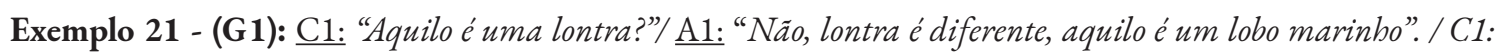

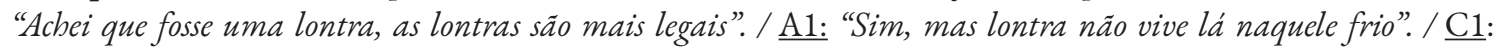
"Aham...prefiro as lontras".

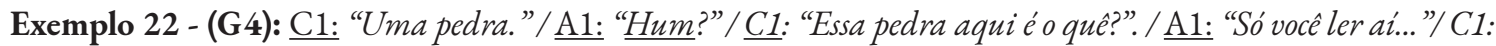
"os.. ostracodes são micro fo..." [lê com dificuldade o painel e pai auxilia] / A1: "Microfósseis \{Leitura\} são pequenos fósseis de crustáceos com o corpo coberto por duas valvas, que viveram em todos ambientes aquáticos desde que o mundo era coberto por oceano". / $\mathrm{C} 1:$ "Hum".

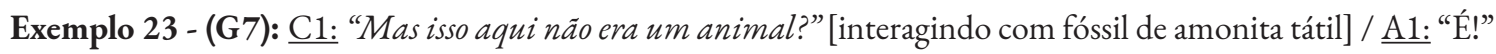

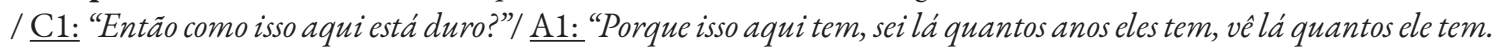
Isso éum fóssil, rapaz." [...]

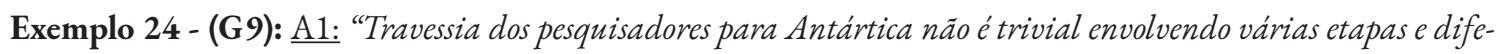
rentes meios de transporte" \{Leitura\} [continuam assistindo o vídeo sobre o tema]. "A lá, um navio daquele igual a gente viu ontem só que maior". / C1: "Uhum” / A1: "Ele vai cortando o gelo, só que ali não é uma plaquinha de gelo não, né?" / $\underline{\mathrm{C} 1}$ : "Não" / $\underline{\mathrm{A} 1}$ : "É um iceberg, pra baixo também tem gelo. Então você imagina o quanto demora, tá vendo como ele vai devagarinho?"/ $\underline{1}$ : "Tem gente que usa esses navios para ajudar baleias porque tem vezes que a baleia fica presa ai embaixo". / 1ㅡ: "É", mas embaixo tem parte de água". / 1ㅗ: "mas baleia precisa subir pra respirar, né?". 
Exemplo 25 - (G1): C1: "Pai, olba só, um tubarão touro". / A1: "Bull shark." \{Leitura\} / C1: "Ali tá escrito sand tiger shark." / A1: "Então isso não éum tubarão touro" / C1: "Aqui tá tubarão touro." / A1: "sand tiger shark" \{Leitura\} "Então, tem uma espécie que é bull shark mesmo, mas como isso é um tubarão touro?... então tá bom. A arcada de tubarão touro que en já vi é bem maior do que essa aqui."/C1: "É uma representação". /

Os trechos de diálogo apresentados acima indicam que a construção de sentido foi realizada quando os participantes estavam identificando ou descrevendo enquanto observavam os elementos do módulo expositivo, como objetos, painéis e vídeos. Fazer comparaçóes, analogias explícitas e implícitas com conhecimentos e/ ou conectar experiências anteriores contribuiu para dar sentido à experiência. Cada exemplo apresenta uma particularidade, mas, em geral, a informação abordada é o disparador para que as famílias compreendam, deem significado e façam associaçóes que contribuem para sua experiência de aprendizagem. Por exemplo, no G1 (Exemplo 21), ao observar o animal taxidermizado, a criança é instruída pelo pai que o animal que ele visualiza é, na verdade, um lobo marinho, e que não poderia ser uma lontra, visto que esses animais não conseguiriam viver em um ambiente de temperatura tão extrema - informação essa que é de conhecimento prévio do pai. A criança demonstra sua preferência pela lontra, mas tem uma resposta que faz sentido para ela. No exemplo 24 do G9, as informaçóes do vídeo associadas a experiências anteriores dão sentido às informações científicas apresentadas para essa família. O navio é comparado pela mãe (A1) a um navio visto no dia anterior e, pela criança, a navios de resgate de animais (C1). Dessa forma, os integrantes da família seguem a discussão para outros conhecimentos científicos sobre a espessura do gelo e a biologia das baleias.

Para finalizar, verificamos que a visita à exposição proporcionou às famílias a aproximação à ciência por ressaltar os pesquisadores de forma humanizada, destacando o trabalho e as pesquisas por eles desenvolvidas, bem como a importância do trabalho em equipe (elementos relevantes para a discussão sobre a natureza da ciência e a produção do conhecimento) - um aspecto importante que contribui para a criação de sentido por parte dos visitantes e que a exposição conseguiu proporcionar. Exemplo disso está na frase da criança do G6 (8 anos) que, ao observar um painel de fotos dos pesquisadores na Antártica, pergunta para a mãe se os pesquisadores são pessoas reais, "Eles são de verdade?”, e, para comprovar que sim, a mãe mostra uma foto dos pesquisadores fazendo comida. Também no G4, o menino mais velho da família questiona a mãe "Eles vão lá pra quê?”, e a mãe responde, "ué, filho, pesquisa”. Há, ainda, comentários feitos pelas famílias sobre como os cientistas sabem o que sabem (Exemplo 19) e usam ferramentas científicas (Exemplo 2). Outros exemplos, como visto no código Atividade Interativa (Exemplos 16 e 18), também ressaltaram a importância de aproximar as famílias do cientista como uma pessoa humana, sem estereótipos. As conversas estabelecidas entre os familiares destacaram as condições em que esses cientistas da exploração da Antártica trabalham, o que vestem, o que comem, ou seja, que os pesquisadores são pessoas comuns e que a ciência nem sempre é produzida em laboratórios, mas também em atividades de campo e exploração.

\section{DISCUSSÃO}

O objetivo deste estudo foi compreender como uma exposição com um design de espaço narrativo pode facilitar o processo de aprendizagem e construção de significado de temas relacionados à ciência. A análise dos resultados evidencia que as famílias foram capazes de desenvolver algum entendimento da exposição "Quando nem tudo era gelo - Novas Descobertas no Continente Antártico" e que as exposiçôes narrativas podem ser articuladas para a construção de significado pelas famílias. Evidências desse processo ocorreram de diferentes formas de envolvimento das famílias. Observamos que a natureza da exposição, com um design mais contemplativo que interativo, demonstrou ser um recurso importante que contribuiu para as interaçóes, em especial para a Leitura de painel/texto/foto explicativo, um aspecto que se mostrou como determinante para as Conversas sobre temas de ciência. Esse resultado é compatível com estudos realizados 
com famílias e que usam o mesmo protocolo de análise deste grupo de pesquisa ( $C f$ : Massarani et al., 2021a; Massarani et al., 2021b). Por exemplo, Massarani et al. (2021a) analisaram os diálogos em família em uma exposição de ciência e verificaram que conversas sobre conteúdos científicos da exposição se destacaram nas conversas. Massarani et al. (2021b), ao investigar a interação de famílias em um museu interativo de ciência, também traz evidências de como a leitura é um tipo de comportamento importante na experiência de visita dos familiares e para o estabelecimento de Conversas sobre temas de ciência. Na mesma direção, To et al. (2016), que analisaram as conversas entre pais e filhos em um museu de história natural, mostram que as famílias que liam o texto das exposiçôes eram mais propensas a permanecer mais tempo nas exposiçôes e encontrar o conteúdo pretendido do que as famílias que não liam o texto.

Neste estudo, observamos como a interação contemplativa dos objetos foi enriquecedora para as interpretações e significados que as famílias constroem a partir deles. Achiam, May e Marandino (2014), ao discutirem o conceito de affordance, ${ }^{1}$ explicam como uma exposição atrai e chama a atenção do visitante sem a intervenção de um mediador humano, e concluem que as características físicas, geométricas ou simbólicas oferecem oportunidades para determinados tipos de interação. Na exposição analisada, objetos que chamavam a atenção, como crânio de baleia, arcada de tubarão touro, modelo de plesiossauro, animais taxidermizados e alguns fósseis, despertaram maior interesse para o entendimento, como vimos nos exemplos 5 (G3) e 8 (G9). Um aspecto que observamos e que evidencia o interesse pelos aparatos mencionados foi o uso do celular como forma de fotografar e registrá-los. Destacamos, ainda, que nesse processo um recurso bastante utilizado pelos familiares foi apontar para os objetos. Por exemplo, frases como "Olha isso", "Ali, tá vendo?", "O que é isso?”, e as descrições presentes em nossas transcrições, como "aponta para”, foram formas recorrentes que indicam o que eles queriam destacar. Isso indica que, para além da óbvia importância do apontar como um gesto para chamar a atenção alheia, elas possibilitaram um bom ponto de partida para a leitura e identificação e nomeação das espécies. Silverman (1995) destaca que muitas das estratégias de criação de significado dos visitantes são, na verdade, comportamentos básicos que estão integrados em nossa vida diária, mas que entendê-los em um espaço museal é fundamental, pois ajuda a direcionar a construção de exposições relevantes e diversamente significativas para as pessoas.

Diferentes estudos (por exemplo, Achiam; May \& Marandino, 2014; Rowe, 2002; Rowe \& Bachman, 2012) têm indicado que os visitantes tentam colocar o que encontram nos museus - textos, objetos, vídeos, fatos, por exemplo - dentro do contexto de sua experiência. Em relação a isso, verificamos que os integrantes das famílias também aproveitavam as características estéticas do objeto para arriscar um palpite sobre o que poderia ser, trocar perguntas com outro membro da família e trazer suas experiências e conhecimentos anteriores, enquanto simultaneamente prosseguiam sua própria investigação sobre determinado objeto. Nas conversas do G1 (Exemplo 25) e G6 (Exemplo 11), há uma expressão evidente de construção de significados a partir da experiência contemplativa proporcionada. No exemplo 25, sobre a identificação do tubarão touro, o pai demonstra ter conhecimento prévio sobre os tubarões: ele questiona se é correta a informação dada pela exposição sobre a espécie do animal, com base no fato de que já tinha visto um exemplar e achava que era de maior porte. E, no exemplo 11, a compreensão do objeto é facilitada pela comparação que a mãe faz do crânio de baleia com o crânio humano (tocando na cabeça da criança) para que ela atribuísse sentido ao que via. Dito isso, nossos resultados indicam que ter a experiência de ver algo "na vida real" que eles haviam lido ou ouvido falar anteriormente se mostrou um aspecto importante da experiência com o objeto. Logo, a recorrência desse tipo de comportamento nos auxiliou a identificar que as famílias criaram significados por meio de um processo constante de lembrar e conectar. Um estudo conduzido por Massarani et al. (2019c) também demonstrou que os objetos de uma exposição de ciência que mais despertaram o interesse, a motivação e a construção de significados em adolescentes foram objetos reais que permitiam, de alguma forma, associá-los com o cotidiano e a sua vida particular, com o seu contexto sociocultural e com suas experiências prévias. 
Rennie et al. (2003) apontam que fatores sociais e culturais, como conversas, manipulaçôes das exposiçóes e agrupamentos de indivíduos (aqui interaçôes entre famílias), medeiam a experiência de aprendizagem de maneiras importantes. No entanto, não é apenas a conversa, mas também a ação e a coordenação das duas que podem revelar a criação de significado. Nesse sentido, diferentes formas de envolvimento das famílias externalizam a construção de significado na exposição. Nossos dados evidenciam que um comportamento recorrente em todas as famílias analisadas está no papel do membro adulto (pai, mãe, avô, avó etc.) em estimular a aprendizagem das crianças como objetivo de interação na experiência de visita. Cerqueira e colaboradores (2016) apontam que um aspecto importante dessa relação é referente ao tema abordado pela exposição, sendo ele que irá direcionar a maneira como o adulto interage com as crianças nas visitas. Shaby e Vedder-Weiss (2020), por exemplo, investigaram, por meio da observação, o posicionamento corporificado e a construção de significado na interação física com a exposição de três estudantes enquanto visitavam um museu de ciências. Como resultado, os autores reforçam que o design físico da exposição moldou a interação física, que inclui a criação de sentido corporificado que molda e é moldado pela identificação social dos participantes. Sobre esse aspecto, é importante destacar que os pais empregaram uma variedade de ferramentas na experiência de visita, como chamar a atenção das crianças para os objetos, ler as legendas e painéis para ela; solicitar que ela lesse por si própria, não oferecendo apenas respostas; utilizar de experiências e conhecimentos anteriores (provenientes de um contexto mais científico e/ou de contextos mais cotidianos).

Somada a isso, a interação de cada família na exposição indicou a presença de experiências de aprendizagem de natureza idiossincrática - com conhecimentos de fundos variados, identidades pessoais e coletivas e modelos culturais diversos (Falk, 2021). As famílias criaram sentido a partir dessas experiências, seja por meio do processamento da ciência por trás delas, seja por encontrar algo pessoalmente significativo nelas (Gutiwill-wise \& Allen, 2002; Zimmerman et al., 2016, 2019). Sobre isso, McClain e Zimmerman (2019) argumentam que quando as famílias estabelecem conexões entre a exposição e suas experiências de vida, haverá maior oportunidade para o crescimento do conhecimento individual e em grupo, compreensão contextualizada da questão e criação de sentido científico com apoio mútuo entre pais e filhos.

Embora Conversas sobre temas de ciência tenha sido um código expressivo de análise, não foram observadas, com frequência, conversas contínuas que demonstrassem um aprofundamento de ideias e conhecimentos de ciência sobre o tema da exposição - conexôes comumente encorajadas pela maioria dos museus (Silverman, 1995).

Ainda que poucos diálogos tenham se aprofundado no tema científico, a narrativa da exposição - que permitiu ver as ferramentas que os paleontólogos utilizaram durante a expedição, o quadriciclo que os locomoveu e as barracas que os abrigaram, além de fotos com momentos que vivenciaram durante o projeto possibilitou, de certa forma, que os familiares compreendessem informações sobre a vida dos cientistas, suas características pessoais e seus campos de atuação (Bayir; Cakicim \& Ertas, 2013). Além disso, apresentou aos visitantes uma imagem não estereotipada do cientista (Castelfranchi et al., 2008; Siqueira, 2008). Promover e perfilhar essas questóes contribui para o reconhecimento da dimensão social e do trabalho coletivo da produção do conhecimento científico (Delizoicov et al., 2002).

\section{CONSIDERAÇÕES FINAIS}

Pela observação dos aspectos mencionados neste estudo, entendemos que a identificação de experiências de construção de sentido se constitui como uma estrutura importante para a compreensão das experiências de aprendizagem das famílias em exposições de ciências. Nosso estudo contribui para esse entendimento de duas maneiras significativas.

Em primeiro lugar, demonstra que as exposições contemplativas com enfoque nos objetos e artefatos têm potencial para envolver as famílias e há evidências de que, em alguns momentos observados, tenham ajudado as famílias a consolidar um processo de construção de significado e compreensão de temas relacionados à ciência. Nesse processo, as conversas analisadas permitem ainda compreender que as famílias fizeram conexóes 
menos formais com o conteúdo, por meio de sínteses de suas atividades cotidianas, compartilhamento de experiências, do que conexôes com o conhecimento científico específico abordado para dar sentido à exposição.

Em segundo lugar, identificamos que comportamentos específicos, como o de leitura, fazer e responder perguntas, apontar, identificar, fazer comparaçóes, observar objetos reais e fazer conexôes com experiências pessoais e anteriores, se mostraram estratégias úteis para contribuir e fortalecer as experiências de aprendizagem sobre o tema abordado. Argumentamos que a exposição com um design de ambiente narrativo favoreceu tais comportamentos e, consequentemente, a construção de significado pelas famílias, em particular em conversas relacionadas à ciência.

Compreendemos que a exposição “Quando nem tudo era gelo” se constituiu de um meio pelo qual conversas significativas puderam ser construídas em família. Cada indivíduo trouxe consigo elementos únicos para compartilhar, o que possibilitou expandir suas ideias e enriquecer o conhecimento dos membros do grupo. Consideramos que abordagens de pesquisas que levem em consideração a construção de significado ativa e distribuída reforçam a natureza social da experiência e fornecem uma boa oportunidade de compreender as atividades de grupo e suas experiências de aprendizagem.

Como os grupos familiares são um grupo frequente nos museus (Falk, 2021), cabe a nós pesquisadores compreender melhor o papel das conversas e interaçôes no processo de aprendizagem durante a dinâmica de visita. Nesse sentido, nosso estudo fornece um exemplo de como as metodologias baseadas no registro audiovisual são importantes para entender melhor como as famílias aprendem. Além disso, pouco se sabe, especialmente no contexto latino-americano, sobre o significado atribuído à experiência de visitas familiares em museus de ciências. Como implicações para a prática, os resultados deste estudo podem auxiliar curadores e educadores de espaços sociais de aprendizagem na concepção de exposições, placas, painéis e atividades, visando tornar a experiência das famílias mais significativa.

\section{AGRADECIMENTOS}

Este estudo foi realizado no escopo do Instituto Nacional de Comunicação Pública da Ciência e Tecnologia, com apoio financeiro das agências de fomento Conselho Nacional de Desenvolvimento Científico e Tecnológico (CNPq, 465658/2014-8) e Fundação Carlos Chagas Filho de Amparo à Pesquisa do Estado do Rio de Janeiro (FAPERJ, E-26/200.89972018). O estudo também se insere no projeto apoiado pelo Edital Universal 2018 do CNPq (405249/2018-7), liderado por Luisa Massarani. A autora Luisa Massarani agradece a Bolsa de Produtividade 1B do CNPq e a Faperj pela bolsa Cientista do Nosso Estado. Os autores Antero Vinícius Portela e Juliana Magalhães de Araújo agradecem à FAPERJ pelas bolsas TCT. A autora Graziele Scalfi agradece ao CNPq por sua bolsa EXP-B. A autora Jessica Norberto Rocha agradece à Faperj pela bolsa Jovem Cientista do Nosso Estado. Agradecemos ao Museu Nacional, por permitir a coleta de dados, e às famílias que aceitaram nosso convite, possibilitando o desenvolvimento deste estudo.

O CECIMIG agradece à CAPES (Coordenação de Aperfeiçoamento de Pessoal de Nível Superior) e à FAPEMIG (Fundação de Amparo à Pesquisa do Estado de Minas Gerais) pela verba para editoração deste artigo.

\section{REFERÊNCIAS}

Achiam, M., May, M., \& Marandino, M. Affordances and distributed cognition in museum exhibitions. Museum Management and curatorship, 29(5), 461-481. 2014.

Allard, M., \& Boucher, S. Éduquer au musée: un modèle théorique de pédagogie muséale. Hurtubise HMH. 1998.

Allen, S. Looking for learning in visitor talk: A methodological exploration. In: Learning conversations in museums 265-309. Routledge. 2003. 
Ash, D. Dialogic inquiry in life science conversations of family groups in a museum. Journal of Research in Science teaching, 40(2), 138-162. 2003.

Ash, D. Reflective scientific sense-making dialogue in two languages: The science in the dialogue and the dialogue in the science. Science Education, 88(6), 855-884. 2004.

Bayir, E., Cakici, Y., \& Ertas, O. Exploring Natural and social scientists' views of nature of science. International Journal of Science Education, 36(8), 1286-1312. 2013.

Borun, M. Object-based learning and family groups. Perspectives on object-centered learning in museums, 245-260. 2002.

Borun, M., Chambers, M. B., Dritsas, J., \& Johnson, J. I. Enhancing family learning through exhibits. Curator: The Museum Journal, 40(4), 279-295. 1998.

Briseño-Garzón, A., \& Anderson, D. A review of Latin American perspectives on museums and museum learning. Museum Management and Curatorship, 27(2), 161-177. 2012.

Castelfranchi, Y., Manzoli, F., Gouthier, D., \& Cannata, I. O cientista é um Bruxo? Talvez não: ciência e cientistas no olhar das crianças. Ciência e criança: a divulgação cientifica para o público infantojuvenil. Rio de Janeiro: Museu da Vida/Fiocruz, 13-18. 2008.

Cerqueira, B., Kuano, R., Nagumo, P., \& Bizerra, A. Aprendizagem familiar Em museus de ciências: interaçóes de pais e mães com exposiçôes científicas. Revista de Ensino de Biologia da Associação Brasileira de Ensino de Biologia (SBEnBio), 9, 6613-6624. 2016.

Conexão Ufrj. Museu Nacional inangura exposição sobre o Continente Antártico. Memória, 2019. Disponível em: $<$ https://conexao.ufrj.br/2019/01/17/museu-nacional-inaugura-exposicao-sobre-o-continente-antartico/>. Acesso em: 05 out. 2020.

Crowley, K., Callanan, M. A., Jipson, J. L., Galco, J., Topping, K., \& Shrager, J. Shared scientific thinking in everyday parent-child activity. Science Education, 85(6), 712-732. 2001.

Delizoicov, D., Castilho, N., Cutolo, L. R. A., Da Ros, M. A., \& Lima, A. M. C. Sociogênese do conhecimento e pesquisa em ensino: contribuiçôes a partir do referencial fleckiano. Caderno Brasileiro de Ensino de Física, 52-69. 2002.

Dierking, L. D. The family museum experience: Implications from research. Journal of Museum Education, 14(2), 9-11. 1989.

Dierking, L. D., \& Falk, J. H. Science education: informal editorial policy statement, 113-113. 1999.

Duarte, L. F. D. O Museu Nacional: ciência e educação numa história institucional brasileira. Horizontes Antropológicos, 25, 359-384. 2019.

Elkonin, D. B. Desarrollo psíquico de los escolares. Psicologia, 523-560. 1969.

Ellenbogen, K. M. Museums in family life: An ethnographic case study. In Learning conversations in museums, 92-112. Routledge. 2003.

Ellenbogen, K. M., Luke, J. J., \& Dierking, L. D. Family learning in museums: Perspectives on a decade of research. In principle, in practice: Museums as learning institutions, 17-30. 2007.

Falk, J. H. The Value of Museums: Enhancing Societal Well-Being, Rowman \& Littlefield Publishers. 2021.

Falk, J. H., \& Dierking, L. D. Visitor experiences and the making of meaning. American Association for State and Local History, 288. 2000.

Falk, J. H., \& Dierking, L. D. Lifelong science learning for adults: The role of Free-choice experiences. In: Second international handbook of science education, 1063-1079. Springer, Dordrecht. 2012.

Falk, J. H., \& Storksdieck, M. Learning science from museums. História, ciências, saúde-Manguinhos, 12, 117-143. 2005.

FAPESP. Museus em crise - edição especial. São Paulo, 78. 2018. 
Faria, C., Guilherme, E., Gaspar, R., \& Boaventura, D. History of science and science museums. Science $\Xi^{\circ}$ Education, 24(7), 983-1000. 2015.

Glăveanu, V. P., \& Lahlou, S. Through the creator's eyes: Using the subjective camera to study craft creativity. Creativity Research Journal, 24(2-3), 152-162. 2012.

Gutwill-Wise, J. Finding Significance: Testing methods for encouraging Meaning-making in a science museum. Current Trends in Audience Research and Evaluation, v. 15, 5-11. 2002.

Jakobsson, A., \& Davidsson, E. Using sociocultural frameworks to understand the Significance of interactions at science and technology centers and museums. In: Understanding interactions at science centers and museums, 3-21. Brill Sense. 2012.

Lahlou, S. How can we capture the subject's perspective? An evidence-based approach for the social scientist. Social science information, 50(3-4), 607-655. 2011.

Lei no 8.069, de 13 de julho de 1990. Dispóe sobre o Estatuto da Criança e do Adolescente. Disponível em <http://www. planalto.gov.br/ccivil_03/leis/18069.htm>. Acesso: 14 out. 2020.

Leichter, H. J., Hensel, K., \& Larsen, E. Families and museums: Issues and perspectives. Marriage E̊ family review, 13(3-4), 15-50. 1989.

Macleod, S., Hanks, L. H., \& Hale, J. (eds.) Museum making: Narratives, architectures, exbibitions. Routledge. 2012.

Marandino, M. Educação em museus: a mediação em foco. São Paulo: Geenf/FEUSP, 1, 48. 2008.

Massarani, L., Fazio, M. E.; Norberto Rocha, J. Dávila, A., Espinosa, S. \& Bognanni, F. A. La Interactividad en los Museos de Ciencias, Pivote entre Expectativas y hechos Empíricos: El caso del Centro Interactivo de Ciencia y Tecnología Abremate (Argentina). Ciência ẼEducação(Bauru), 25(2), 467-84. 2019a. https://doi.org/10.1590/1516731320190020012

Massarani, L., Mucci Poenaru, L., Norberto Rocha J., Rowe, S. \& Falla, S. Adolescents learning with exhibits and explainers: the case of Maloka, International Journal of Science Education, Part B, 9, (3), 253-267. $2019 \mathrm{~b}$.

Massarani, L., Norberto Rocha, J., Mucci Poenaru, L., Bravo, M., Singer, S. e Sánchez, E. “O olhar dos adolescentes em uma visita ao Museo Interactivo de Economía (MIDE), México”, Revista Iberoamericana de Ciencia, Tecnología y Sociedad -CTS, 15(44),173-195. 2020.

Massarani, L., Norberto Rocha, J., Scalfi G., Silveira Y., Cruz, W. \& Lage dos Santos Guedes L. Families Visit the Museum: A Study on Family Interactions and Conversations at the Museum of the Universe - Rio de Janeiro (Brazil). Front. Educ. 6:669467. 2021b. http://dx.doi.org/10.3389/feduc.2021.669467

Massarani, L., Reznik, G., Rocha, J. N., Falla, S., Rowe, S., Martins, A. D., \& Amorim, L. H. A Experiência de Adolescentes Ao Visitar Um Museu De Ciência: Um Estudo No Museu Da Vida. Ensaio Pesquisa Em Educação Em Ciências (Belo Horizonte), 21, 1-25. 2019c. https://doi.org/10.1590/1983-21172019210115

Massarani, L., Scalfi, G., Norberto-Rocha, J., Velloso Luz, R. \& Marandino, M. A experiência interativa de famílias em um museu de ciências: um estudo no Museu de Ciência e Tecnologia de Porto Alegre. Revista Investigaçóes em Ensino de Ciências (IENCI), 26, 1, 261-284. 2021a. http://dx.doi.org/10.22600/15188795.ienci2021v26n1p261

McClain, L. R. \& Zimmerman, H. T. Family connections to local science issues: how scientists use questions to engage families in personally-relevant learning during science-themed workshops, International Journal of Science Education, Part B, 9(2), 154-170. 2019.

McClain, L. R., \& Zimmerman, H. T. Memories on the Trail: Families Connecting their Prior Informal Learning Experiences to the Natural World during Nature Walks. Journal of Interpretation Research, 21(2), 21-42. 2016.

McManus, P. Families in museums. Towards the museum of the future: New European perspectives, 81-97. 1994.

Moussouri, T. Family agendas and family learning in hands-on museums. University of Leicester (Reino Unido). 1997.

Pedretti, E. G. Perspectives on learning through research on critical issues-based science center exhibitions. Science Education, 88(S1), S34-S47. 2004. 
Pekarik, A. J., Doering, Z. D., \& Karns, D. A. Exploring satisfying experiences in museums. Curator: The Museum Journal, 42(2), 152-173. 1999.

Pires, D. O. (Org.). 200 anos do Museu Nacional. 1. ed. Rio de Janeiro: Associação Amigos do Museu Nacional, 40. 2017.

Rahm, J. Emergent learning opportunities in an inner-city youth gardening program. Journal of Research in Science Teaching: The Official Journal of the National Association for Research in Science Teaching, 39(2), 164-184. 2002.

Ramey-Gassert, L., Walberg III, H. J., \& Walberg, H. J. Reexamining connections: Museums as science learning environments. Science education, 78(4), 345-363. 1994.

Rennie, L. J., Feher, E., Dierking, L. D., \& Falk, J. H. Toward an agenda for advancing research on science learning in out-of-school settings. Journal of research in Science teaching, 4O(2), 112-120. 2003.

Rodrigues, M. Ciência em meio ao fogo e ao gelo. Ciência e Cultura, 71(2), 12-13. 2019.

Rowe, $S$. The role of objects in active, distributed meaning-making. Perspectives on object-centered learning in museums, 19-35. 2002.

Rowe, S., \& Bachman, J. Mediated action as a framework for exploring learning in informal settings. In: Putting theory into practice (pp. 143-162). Brill Sense. 2012.

Rowe, S., \& Nickels, A. Visitor motivations across three informal education Institutions: An application of the identityrelated visitor motivation model. Visitor Studies, 14(2), 162-175. 2011

Scalfi, G. Crianças em visitas familiares a museus de ciências: análise do processo de alfabetização científica. (Tese de doutorado). Faculdade de Educação, Universidade de São Paulo, São Paulo, SP. 2020. https://doi. org/10.11606/T.48.2020.tde30092020191540

Shaby, N., \& Vedder-Weiss, D. Science identity trajectories throughout school visits to a science museum. Journal of Research in Science Teaching, 57(5), 733-764. 2020.

Shaby, S., O Ben-Zvi Assaraf, \& Tal, T. Engagement in a science museum-The role of social interactions. Visitor Studies $22(1), 1-20.2019$.

Silverman, L. H. Visitor meaning-making in museums for a new age. Curator: The Museum Journal, 38(3), 161-170. 1995.

Siqueira, D. Da C. O. Conhecimento, ciência e escola: representações em desenhos animados. In: Massarani, L. (Ed.) Ciência e Criança: a divulgação científica para o público infanto-juvenil. Rio de Janeiro: Museu da Vida/Casa Oswaldo Cruz/Fiocruz, 41-48. 2008.

Tal, T. Out-of-School: Learning Experiences, Teaching and Students' Learning. In: Fraser, B., Tobin, K., \& McRobbie, C. J. (Eds.) Second international handbook of science education (Vol. 24). Springer Science \& Business Media. 2012.

To, C., Tenenbaum, H. R., \& Wormald, D. What do parents and children talk about at a Natural History Museum?. Curator the Museum Journal, 59(4), 323-459. 2016.

Vigotsky, L. Estudio del desarrollo de los conceptos científicos en la edad escolar. Obras escogidas, 2, 9-348. 1993.

\section{NOTAS}

1 Qualidade de um objeto que permite ao indivíduo identificar sua funcionalidade sem necessidade prévia de explicação.

\section{Luisa Massarani}

Titulação: Doutora em Gestão, Educação e Difusão em Biociências (Universidade Federal do Rio de Janeiro)

Afiliação institucional: Instituto Nacional de Comunicação Pública da Ciência e Tecnologia (INCT-CPCT); Casa de Oswaldo Cruz/Fiocruz, Rio de Janeiro, RJ, Brasil.

E-mail: luisa.massarani@fiocruz.br 


\section{Julia Botelho Pereira}

Titulação: Mestre em Divulgação de Ciência, Tecnologia e Saúde da Casa de Oswaldo Cruz - Fiocruz

Afiliação institucional: Museu de Astronomia e Ciências Afins - MAST, Rio de Janeiro, RJ, Brasil.

E-mail: juliabotelhopereira@gmail.com

\section{Graziele Scalfi}

Titulação: Doutora em Educação (FE/USP)

Afiliação institucional: Instituto Nacional de Comunicação Pública da Ciência e Tecnologia (INCT-CPCT), Rio de Janeiro, RJ, Brasil.

E-mail: graziscalfi@gmail.com

\section{Antero Vinícius Portela Firmino Pinto}

Titulação: Graduado em Geografia e Meio Ambiente

Afiliação institucional: Instituto Nacional de Comunicação Pública da Ciência e Tecnologia (INCT-CPCT), Rio de Janeiro, RJ, Brasil.

E-mail: anterovinicius@gmail.com

Juliana Magalhães de Araújo

Titulação: Doutora em Ecologia e Evolução (UERJ)

Afiliação institucional: Instituto Nacional de Comunicação Pública da Ciência e Tecnologia (INCT-CPCT), Rio de Janeiro, RJ, Brasil.

E-mail: dearaujojm@gmail.com

\section{Jessica Norberto Rocha}

Titulação: Doutora em Educação (FE/USP)

Afiliação institucional: Fundação Centro de Ciências e Educação Superior à Distância do Estado do Rio de Janeiro, Fundação CECIERJ, Rio de Janeiro, RJ, Brasil.

E-mail: jessicanorberto@yahoo.com.br

\section{Contato:}

Luisa Massarani

Fiocruz, Casa de Oswaldo Cruz, Centro de Documentação e História da Saúde (CDHS)

Av. Brasil, 4365 - Manguinhos

Rio de Janeiro - RJ | Brasil

CEP 21.040-900

Editor responsável:

Vanessa Cappelle

Contato:

Centro de Ensino de Ciências e Matemática de Minas Gerais - CECIMIG

Faculdade de Educação - Universidade Federal de Minas Gerais

revistaepec@gmail.com 